\title{
Método bola de neve em pesquisa qualitativa com travestis e mulheres transexuais
}

\author{
Snow ball method in qualitative research with sheets and transexual women \\ Método de bola de nieve en investigación cualitativa con sábanas y mujeres transexuales
}

\begin{abstract}
RESUMO
Objetivo: relatar a experiência da utilização da amostragem bola de neve como possibilidade para pesquisas em enfermagem com travestis e mulheres transexuais. Método: trata-se de um estudo descritivo, do tipo relato de experiência, que descreve a utilização da amostragem em bola de neve para a criação de redes de referências de uma pesquisa qualitativa, realizada em 2018, que teve como participantes travestis e mulheres transexuais. Resultados: a amostragem de bola de neve permitiu encontrar a população de estudo por meio de suas informantes chave, denominadas Sementes, que facilitou a construção de uma rede de contatos, além de terem sido mediadoras para o agendamento dos encontros, culminando no desenrolar da etapa de coleta dos dados. Conclusão: esta experiência demonstrou a importância da utilização do método bola de neve em pesquisas em enfermagem cuja população a ser estudada conviva com uma condição de invisibilidade social ou quando a temática aborda assuntos de cunho íntimo.
\end{abstract}

DESCRITORES: Pesquisa em Enfermagem; Travestilidade; Transexualidade.

\section{ABSTRACT}

Objective: to report the experience of using snowball sampling as a possibility for nursing research with transvestites and transsexual women. Method: this is a descriptive study, of the experience report type, which describes the use of snowball sampling for the creation of networks of references from a qualitative research, held in 2018, which involved transvestites and transsexual women. Results: the snowball sampling allowed the study population to be found through its key informants, called Seeds, which facilitated the construction of a network of contacts, in addition to being mediators for scheduling meetings, culminating in the development of the stage data collection. Conclusion: this experience demonstrated the importance of using the snowball method in nursing research whose population to be studied lives with a condition of social invisibility or when the theme addresses issues of an intimate nature.

DESCRIPTORS: Nursing Research; Transvestism; Transsexualism.

\section{RESUMEN}

Objetivo: relatar la experiencia de utilizar el muestreo de bola de nieve como posibilidad de investigación en enfermería con travestis y mujeres transexuales. Método: se trata de un estudio descriptivo, del tipo relato de experiencia, que describe el uso del muestreo bola de nieve para la creación de redes de referencias de una investigación cualitativa, celebrado en 2018, que tuvo como participantes a travestis y mujeres transexuales. Resultados: el muestreo de bola de nieve permitió encontrar la población de estudio a través de sus informantes clave, denominados Semillas, lo que facilitó la construcción de una red de contactos, además de ser mediadores para programar reuniones, culminando con el desarrollo de la etapa de recolección de datos. Conclusión: esta experiencia demostró la importancia de utilizar el método bola de nieve en la investigación en enfermería cuya población a estudiar vive con una condición de invisibilidad social o cuando el tema aborda temas de carácter íntimo.

DESCRIPTORES: Investigación em Enfermería. Travestismo. Transexualidad.

RECEBIDO EM: 31/05/2021 APROVADO EM: 04/06/2021

\section{Guilherme Sacheto Oliveira}

Mestre em Enfermagem. Professor do Curso de Graduação em Enfermagem. Fundação São José de Itaperuna.

ORCID: 0000-0003-2642-7320 


\section{Zuleyce Maria Lessa Pacheco}

Doutora em em Enfermagem. Professora do Curso de Graduação em Enfermagem. Universidade Federal de Juiz de Fora. ORCID: 0000-0002-9409-8971

\section{Anna Maria de Oliveira Salimena}

Doutora em Enfermagem. Professora do Curso de Graduação em Enfermagem. Universidade Federal de Juiz de Fora. ORCID: 0000-0001-7799-665X

\section{Camila Messias Ramos}

Mestre em Enfermagem. Enfermeira da Fundação Hospitalar do Estado de Minas Gerais. FHEMIG. ORCID: 0000-0001-9156-8328

\section{Alanna Fernandes Paraíso}

Doutora em Ciências da Saúde. Professora do Curso de Graduação em Enfermagem. Universidade Federal de Juiz de Fora. ORCID: 0000-0001-7400-140X

\section{INTRODUÇÃO}

A sociedade contemporânea se organiza a partir de uma definição binária de gênero, construída historicamente por relações de saber e de poder, encaminhando as pessoas para o "mundo" masculino ou feminino desde o nascimento, tendo como efeito a instauração da cisnormatividade, uma norma que produz também o domínio de corpos preteridos e ignóbeis, sendo responsável pela exclusão e marginalização das identidades consideradas ininteligíveis aos padrões sociais vigentes. A ordem de gênero está presente em nossos corpos, identidades, economia, comportamentos, vestimentas e linguagem ${ }^{(1)}$.

Embora a cisnormatividade seja vista como padrão, cada ser é capaz de construir sua própria identidade de gênero, ultrapassando as barreiras do masculino e feminino. Romper esta barreira é algo vivenciado por travestis e mulheres transexuais: ambas são marcadas ao nascer como sendo pertencentes ao gênero masculino, porém apresentam uma compreensão social construída de si que as localiza no universo do gênero feminino ${ }^{(1-3)}$.

O Ministério da Saúde apresenta como definição em seus formulários de atenção básica que travesti é um homem no sentido anatomofisiológico, mas se relaciona com o mundo como mulher, moldando seu corpo com formas femininas (por meio do uso de hormônios feminilizantes e/ou aplicações de silicone). As mulheres transexuais são pessoas cuja identidade de gênero é oposta ao sexo biológico, ou seja, são psicologicamente de um sexo/gênero e anatomicamente de outro, e neste sentido desejam ser aceitas e respeitadas de acordo com sua autodeclaração ${ }^{(4)}$. No presente estudo designaremos travestis e mulheres transexuais como pessoas trans.

Pessoas trans historicamente foram patologizadas nos discursos médico-psiquiátricos, porém na atualidade devido mudanças políticas e sociais, reflexos da luta e resistência destes grupos, elas deixaram de ser vistas como portadoras de transtorno mental e a essas categorias se agregam parâmetros filosóficos, epistemológicos e sociais, que vem contribuindo para a despatologização e integralidade da assistência ${ }^{(1,45)}$.

Em nossa sociedade o processo de desenvolvimento econômico se mostra atrelado, no âmbito social, por inúmeras desigualdades e falta de investimentos ${ }^{(6)}$. As pessoas trans são as que sofrem maior preconceito e discriminação, tanto em ambiente familiar e social quanto nos serviços de saúde, seja pela transfobia ou pela discriminação atrelada a pobreza, raça/cor, aparência física ou escassez de serviços de saúde específicos. Estar à margem do padrão heteronormativo ainda se configura uma situação de risco em que violações de direitos são cometidas com frequência e por motivações diversas ${ }^{(7-8)}$.

No processo de busca por pessoas trans para atender aos critérios de inclusão de uma pesquisa científica desenvolvida no Curso de Pós-Graduação Mestrado em Enfermagem da Universidade Federal de Juiz de Fora, houve, a princípio, grande dificuldade em acessar as participantes, pois elas evitam utilizar os serviços públicos de saúde onde encontram como barreiras a dificuldade de diálogo com os profissionais de saúde, o desrespeito ao seu nome social, além da oferta de um modelo médico-curativista voltado para a patologização de sua autodeclaração que se mostra incapaz de responder suas demandas de saúde de forma integral ${ }^{(9-11)}$.

Partimos da identificação das que se autodeclaram, impedindo que julgamentos prévios e definições apriorísticas façam parte dos critérios de inclusão utilizados e encontramos na amostragem bola de neve a possibilidade de acessar a população de travestis e mulheres transexuais.

Neste contexto, este estudo tem como objetivo relatar a experiência da utilização da amostragem em bola de neve como possibilidade para pesquisas em enfermagem com travestis e mulheres transexuais.

\section{MÉTODO}

Trata-se de um relato de experiência de abordagem crítico-reflexiva, acerca da utilização da amostragem em bola de neve para a criação de redes de referências de uma pesquisa qualitativa fundamentada na fenomenologia de Martin Heidegger, desenvolvida com dez participantes travestis e mulheres transexuais.

Este estudo foi desenvolvido em 2018 em um município do interior de Minas Gerais e atendeu às normas de ética em pesquisa com seres humanos, tendo sido aprovado pelo Comitê de Ética em Pesquisa da Universidade Federal de Juiz de Fora mediante CAAE 68776017.0.0000.5147. 


\section{RELATO DE EXPERIÊNCIA}

A Bola de neve (snowball sampling ou link-tracing) é uma amostragem não probabilística que utiliza cadeias de referência construídas a partir de pessoas que compartilham algumas características que são de interesse do estudo ou sabem de outras que as possuem. Trata-se de um método aplicável quando o objeto de estudo é composto por grupos de difícil acesso ou quando o estudo busca investigar assuntos privados. Essa técnica possibilita o contato com populações de difícil acesso ou portadoras de peculiaridades. É um processo econômico, que requer planejamento, porém se utiliza de poucos recursos humanos. Em relação aos inconvenientes, cabe citar a falta de controle sobre a constituição e tamanho da amostra ${ }^{(12-14)}$.

A criação da rede de contatos e encontros fenomenológicos constituiu-se cumprindo as seguintes etapas:

Etapa 1: para a utilização da amostragem em bola de neve, inicialmente foram identificadas possíveis informantes-chaves (denominadas de sementes) que poderiam acessar participantes que se declarassem como travestis ou mulheres transexuais. As sementes auxiliam o pesquisador a iniciar seus contatos e a se aproximar do grupo a ser estudada ${ }^{(12)}$. As duas participantes iniciais foram travestis e mulheres transexuais cadastradas pela equipe de saúde da família lócus de um dos pesquisadores. Posteriormente, outras sementes foram acessadas para conformação da rede de contatos.

Etapa 2: agendou-se um local de escolha das participantes para realização do encontro, mediante orientação prévia de que o lugar deveria proporcionar conforto e privacidade, com a presença somente do pesquisador e da participante. Utilizou-se para coleta das informações uma entrevista aberta composta por questões que permitiram interação com as participantes. A partir do momento em que não surgiram novos significados, a etapa de coleta de informações foi finalizada.

Etapa 3: Após cada encontro, foi solicitado às participantes indicadas pela semente que apontassem outros contatos, dentro de sua rede social, com as características desejadas pelo pesquisador. Destarte, o número de participantes pode aumentar a cada entrevista.

Após cada encontro, as entrevistas gravadas em arquivos de áudio foram transcritas na íntegrae lidas exaustivamente. Também, elaborou-se um diário de campo no qual as expressões não verbais das entrevistas eram descritas. A rede de contato tornou-se saturada quando as sementes indicaram participantes que já haviam sido sugeridas anteriormente.

\section{Descrição da Experiência}

Durante sua constituição, duas pessoas recusaram-se a participar do estudo, e uma participante não se enquadrou nos critérios de inclusão elaborados inicialmente: se autodeclarar como travesti ou mulherestransexuais, com idade igual ou superior a 18 anos, independentemente da cor, religião e orientação sexual, ser munícipe e utilizar ao menos um dos serviços de saúde do SUS oferecidos no município em questão. O detalhamento da rede de contatos acessados pode ser observado na Figura 1.
Figura 1 - Rede de contatos acionados

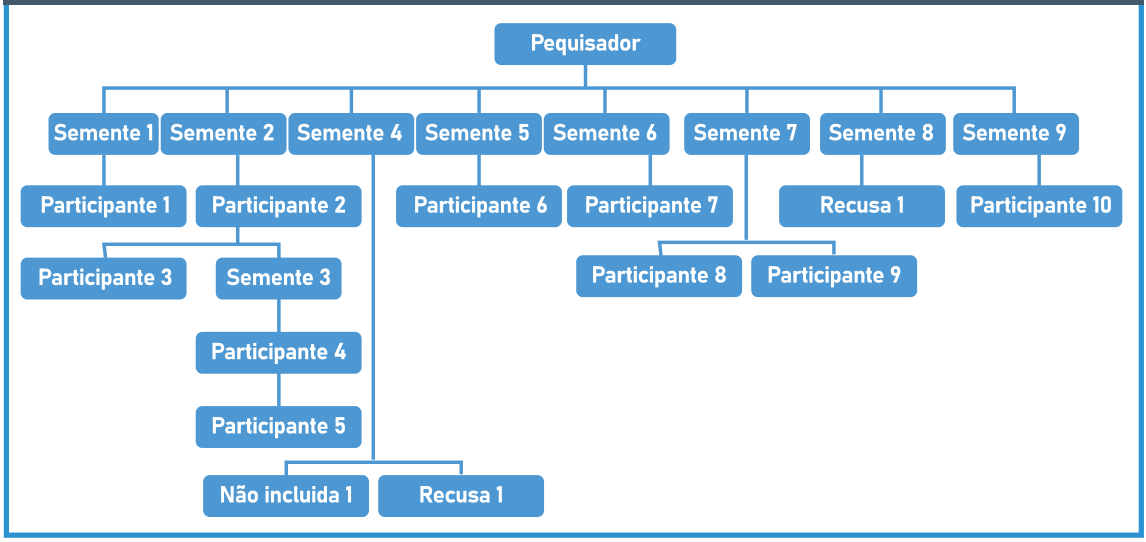

A semente 1 foi a participante inicialmente acessada através de contato direto, por se tratar de uma usuária cadastrada no território de atuação de um dos pesquisadores. Ela atendeu aos critérios de inclusão no estudo e por consequência foi a participante 1 .

A semente 2, também participante, fez a indicação de duas potenciais participantes que foram incluídas no estudo. Após o encontro com a semente 3/participante 4, foi possível o encontro com a participante 5 .

Por indicarem participantes já acessadas, foi preciso que o pesquisador buscasse novas sementes. Acredita-se que a repetição das indicações para a formação da rede de contatos se deve ao fato de o município cenário deste estudo ser classificado como de pequeno porte.

A semente 4 foi uma enfermeira que atua na atenção básica. Durante o encontro com as possíveis participantes, uma não se identificou como travesti, sendo excluída do estudo. A segunda participante em potencial se recusou a participar. Acredita-se que esse fato seja reflexo da condição de invisibilidade na qual estão inseridas. Nesses casos, não foi solicitado que as mesmas indicassem potenciais participantes.

As demais sementes ${ }^{(5,6,7,8 \mathrm{e} 9)}$ foram profissionais de saúde da rede assistencial do município que indicaram participantes incluídas no estudo $(6,7,8,9$ e 10). Após cada encontro, solicitou-se a sugestão de novas participantes, porém as pessoas indicadas já haviam sido abordadas anteriormente. Por questões éticas, o pesquisador não relatava quais participantes já haviam sido contatadas.

\section{DISCUSSÃO}

$\mathrm{O}$ acesso as participantes por meio deste método proporcionou interação satisfatória entre o pesquisador e essa população, já que este encontro não era mais entre desconhecidos. O fato de serem as sementes responsáveis por mediar o encontro entre o pesquisador $\mathrm{e}$ as participantes facilitou a realização dos encontros, uma vez que, sendo o pesquisador alguém conhecido da semente, a participante não demonstrou estranhamento, proporcionando o desvelamento do ser. Portanto, o pesquisador foi reconhecido como uma pessoa que busca a compreensão do modo de vida das participantes. 
A Política Nacional de Saúde Integral de Lésbicas, Gays, Bissexuais, Travestis e Transexuais (LGBT) propõe, entre outros, o incentivo e a realização de pesquisas científicas, inovações tecnológicas e compartilhamento dos avanços terapêuticos voltados às necessidades de saúde desta população ${ }^{(14)}$.

Para tal, é necessário dar voz as travestis e transexuais, uma vez que, entre a população LGBT, estas são as que mais sofrem com preconceitos e discriminação nos ambientes social e familiar. Por extensão, também são as que mais vivenciam preconceitos nos serviços de saúde ${ }^{(15)}$.

A autodeclaração da identidade de gênero registrada nos formulários da atenção primária em saúde mostrou-se como um dos modos de mapear a população desejada para a pesquisa, já que a utilização da amostragem em bola de neve requer que os pesquisadores tenham conhecimento sobre informantes-chaves inseridos na população a ser estudada, antes de iniciar o procedimento de coleta de dados.

Por se tratar de uma população que vivência a invisibilidade, o encontro mediado por pessoas semelhantes pode minimizar um dilema ético, pois o pesquisador não lançou mão de julgamentos prévios, categorizando aqueles que vivenciam a travestilidade e transexualidade e sim, buscou os próprios membros desta rede de contatos a fim de que selecionassem aqueles que se viam socialmente como travestis ou transexuais.

\section{CONSIDERAÇÕES FINAIS}

A amostragem em bola de neve foi uma ferramenta apropriada para a pesquisa com pessoas trans que no cotidiano convivem com a invisibilidade e geralmente se relacionam em rede com os que apresentam características semelhantes à sua e que no caso deste método as características são definidas pelo próprio participante. Por intermédio da formação da rede de contatos, foi possível alcançar a saturação das informações necessárias, as quais viabilizaram o desenvolvimento da pesquisa.

Como limitação do estudo, esta pesquisa se deu circunscrita à realidade vivenciada por pessoas trans que utilizavam o serviço público vinculado ao SUS, portanto não incluiu aquelas que utilizam apenas os serviços de saúde privados. ఐ

\section{REFERÊNCIAS}

1. Grade C, Gross CB, Ubessi LD. Patologização da transexualidade a partir de uma revisão integrativa.Psic. saúde \& doenças 2019 Ago; 20(2):435-451. DOI: 10.15309/19psd200213.

2. Winter S, Diamond M, Green J, Karasic D, Reed T, Phys GD, Whitle $S$ et al. Transgender people: health at the margins of society. Lancet 2016 Jun; 388(10042):390-400. DOI:10.1016/ S0140-6736(16)00683-8.

3. Pontes JC, Silva CG. Cisnormatividade e passabilidade: deslocamentos e diferenças nas narrativas de pessoas trans. Periódicus 2018 Nov;1(8):396-417. Disponivel em: https://periodicos.ufba. br/index.php/revistaperiodicus/article/view/23211/15536. Acesso em: 25 dez. 2020.

4. Ministério dos Direitos Humanos (BR). Secretaria Nacional de Cidadania. Manual Orientador Sobre Diversidade. Brasília, DF: Ministério dos Direitos Humanos, 2018. Disponivel em: http:// www.dedihc.pr.gov.br/arquivos/File/2018/ManualLGBTDIGITALmdh.pdf. Acesso em: 25 dez. 2020.

5. Abreu PD, Ferreira ACP, Araújo EC. A discussão em torno da categoria transexual. Revista de Enfermagem UFPE. 2017 Jun; 11(6). DOI: 10.5205/01012007.

6. Allan DS, Maria A, Melo SV, Glebson M, Oliveira MA, Gomes KC. Tendência temporal e características epidemiológicas da tuberculose em um município do nordeste do Brasil. Revista Cubana de Enfermería. 2019; 34(4). Disponível em: http://www.revenfermeria.sld.cu/index.php/enf/article/view/1557. Acesso em: 25 dez. 2020.

7. Rocon PC, Sodré F, Rodrigues A, Barros MEB, Wandekoken KD. Desafios enfrentados por pessoas trans para acessar o processo transsexualizador do Sistema Único de Saúde. Interface 2019 Aug; 23:2-14. DOI: 10.1590/interface.180633.

8. Silva GWS, et al. Situações de violência contra travestis e transexuais em um município do nordeste brasileiro. Rev.
Gaúcha Enferm. 2016; 37(2): e56407. DOI: 10.1590/19831447.2016.02.56407.

9. Souza MHTD, Pereira PPG. Health care: thetransvestitesof Santa Maria, Rio Grande do Sul, Brazil. Texto contexto -enferm. 2015 Jan; 24(1):146-153. DOI: 10.1590/010407072015001920013.

10. Rocon PC et al. 0 que esperam pessoas trans do Sistema Único de Saúde?. Interface 2018; 22(64): 43-53. DOl: 10.1590/1807-57622016.0712.

11. Silva LKM, Silva ALMA, Coelho AA, Martiniano CS. Uso do nome social no Sistema Único de Saúde: elementos para o debate sobre a assistência prestada a travestis e transexuais. Physis: Revista de Saúde Coletiva 2017; 27(3): 835-846. DOI: 10.1590/s0103-73312017000300023.

12. Saint S, Harrod M, Fowler KE, Houchens N. How Exemplary Teaching Physicians Interact with Hospitalized Patients. J. Hosp. Med 2017;12(12):974-978.DOI: 10.12788/jhm.2844.

13. Fehr AVD, Solberg J, Bruun J. Validation of networks derived from snowball sampling of municipal science education actors. International Journal of Research \& Method in Education 2016 Jun; 41(1):38-52. DOI: 10.1080/1743727X.2016.1192117.

14. Ministério da Saúde (BR). Secretaria de Gestão Estratégica e Participativa. Política Nacional de Saúde Integral de Lésbicas, Gays, Bissexuais, Travestis e Transexuais. Brasília, DF: Ministério da Saúde, 2013. Disponivel em:https://bvsms.saude.gov.br/bvs/ publicacoes/politica_nacional_saude_lesbicas_gays.pdf. Acesso em: 25 dez. 2020.

15. Martinho NJ; Santos VHM CAM, Mart CB; Bacani ES, Morae RSV, Ramos, KCAR. Dificuldades enfrentadas no acesso à saúde por usuários LGBT. Saúde Coletiva (Barueri) 2020, 58: 3841-3848,. MPM Comunicacao. DOI: 10.36489/saudecoletiva.2020v10i58p3841-3848. 